\title{
11
}

\section{HEALTH AND WELL-BEING}

\author{
Alison Charles
}

You are surrounded by many challenges: digital transformation and the benefits and threats that they bring to your business and to your position in the market. Are your competitors hunting you down? What are your economic challenges? As a director, you are facing all of these things - and these are the easy topics to focus on. However, are you neglecting your most valuable resource, missing the biggest lever for your success as a business your people? Do you have a strong employer brand, or do you struggle to attract and retain the right people?

When there is no active well-being strategy, the likelihood is you are losing productivity and impacting your bottom line. That is without even considering the moral imperative. A strategic well-being policy enables you (the board) to discharge your responsibilities and comply with regulatory and legal obligations. It also enables you to have healthy, happy, productive staff.

Employees are being squeezed between the need to work smarter and do more with less. The pressure of the "always on" lifestyle of modern technology brings with it the digital integration between workplace and home. There is tremendous uncertainty in the current work climate, and 
employee health and well-being have never been more important. The way people are managed and engaged are now bottom-line issues, with a need for all organisations to create cultures that enhance well-being and help people thrive.

As well as benefiting individuals, improved employee engagement and well-being build business resilience, performance, and productivity. Strategic health and well-being programmes require a significant degree of planning from the outset. Alignment with the organisation's broader business plan is critical for success. Board involvement/direction/backing/ vision is vital for embedding the health and well-being strategy in corporate culture. It needs a long-term, sustained culture-change programme until it becomes the normal way of doing business.

\section{Strategy and return on investment}

- What steps does the board take to discover the well-being challenges of the organisation?

- Does the organisation have a well-being strategy?

- What is the reputational impact (risk) of not having a well-being strategy?

- How do you link the health and well-being of the workforce to the success of the business?

- How do you demonstrate ROI and value?

- What is your well-being spend and how is it structured? Is it fragmented?

- How do you shift the company away from reactive spending, on managing problems like absenteeism, to proactive spending on supporting and engaging all employees?

- What do you report to shareholders and investors, and what is important to them?

Measuring return on investment (ROI) should be relatively easy. Employee engagement, employee turnover, absenteeism, exit interviews, new employee training, who is performing well, and the impact on the organisation are all measures you could use. All the data should be readily available if you just join it up.

By developing a health and well-being strategy, rather than just a collection of benefits, you can ensure that what you're offering your employees helps 
support the company's wider business objectives. For example, if your business is looking to reduce employee absenteeism through sickness by $25 \%$, you could ensure that your benefits focus on helping employees stay healthy, or return to work more quickly if they have been struck down by an illness. Alternatively, if you want to improve staff retention, you should research what benefits would appeal to your staff the most and incorporate those into your strategy.

By linking the well-being strategy to the company's objectives, it also enables you to set key performance indicators, showing how the strategy can improve these areas. This in turn could help achieve senior management buy-in. Publicly reporting people measures, including well-being-related ones like absenteeism, flexible working, parental leave take-up, and staff satisfaction, are important to your shareholders and investors. It also helps your reputation, recruitment, and retention, and in a talent war makes you the employer of choice. The cost of dealing with absenteeism, lost productivity, and staff turnover is disproportionately high and only focuses on a proportion of the workforce. Wouldn't you rather pay less, channelling the funds to engage with every employee more effectively?

\section{Employee engagement}

- Do you claim that employee mental health and well-being is a priority in the workplace?

- How do your employees believe/know you care about their well-being?

- How do you keep relevant and sustain engagement?

- How do you know the company is using the most effective means to engage all employees?

- What are you doing to directly remove the stigma of talking about mental health issues?

- Do you understand what is important to your employees?

The most effective strategy is a holistic approach to well-being, in which mental health, physical health, training, and personal development are the essential building blocks to help employees fulfil their potential and be resilient.

There is a whole generation sandwiched between the need to look after their children and their parents at the same time, while holding down a job 
or making a career. There is a younger generation that will be retiring much later, if at all, who can't afford to get on the property ladder. The modernday Employee Value Proposition (Benefits) has to provide different people, at different stages in their life, with what they need. It is not just about the amount of remuneration you offer. Truly engaged employees who feel the company really cares about their well-being are productive, healthy, and happy and are the advocates of your business.

\section{Benchmarking}

- What are you doing to strengthen and measure employee engagement activity relative to the competition?

- How do you or will you benchmark your well-being policy?

- Will you/what will you publicly report?

- Is benchmarking simply a cosmetic exercise, or does it express genuine willingness to adopt a powerful well-being strategy?

Recent research ${ }^{1}$ based on FTSE 100 companies, found a positive/significant link between strong people management and organisational performance. Those that have robust arrangements for reporting on employee engagement and well-being outperform the rest of the FTSE 100 by $10 \%$.

\section{Business structure}

A coherent well-being strategy can only be developed by the board linking together HR, health and safety, and occupational health.

- Are the business functions organised in such a way well-being can be managed in a cohesive manner?

- How is the well-being strategy and policy managed?

- How are managers supported and trained? How do you know the support and training is appropriate and effective?

- Do you share your own stories and encourage others to do the same?

1 Research by Business in the Community (BITC) Workwell, 2019 
The well-being policy is derived from the well-being strategy. Typically, this is managed by an HR professional or a similarly suitable role. Well-being must be linked to business objectives, such as the organisation's creativity and innovation, and be able to report back on these metrics.

\section{In conclusion}

For the majority of employees, mental health is still a no-go area, a subject that cannot be discussed with colleagues or managers for fear of discrimination and victimisation. It is time to take break the culture of silence and take action to make your company the employer of choice. Unless the board is actively promoting and seen to be promoting well-being in every level of the business, the strategies and policies that are developed will count for nothing.

- Does the board truly understand the threat of the well-being crisis on the business's objectives or the upside potential when every employee is actively engaged?

- Are you throwing opportunities away? 